\title{
Combinatorial Portfolio Selection with the ELECTRE III method: Case study of the Stock Exchange of Thailand (SET)
}

\author{
Veera Boonjing \\ International College, \\ King Mongkut's Institute of \\ Technology Ladkrabang, \\ Ladkrabang, Bangkok, Thailand \\ (email: veera.bo@kmitl.ac.th)
}

\author{
Laor Boongasame \\ Department of Business Computer, \\ Bangkok University, Bangkok, \\ Thailand (email: laor.b@bu.ac.th)
}

\begin{abstract}
Various techniques of portfolio selection are applied to interpret the status of the market and predict the market's future trend, but they are not beneficial to small investors because these techniques should be administered by an expert. In addition, these techniques desire accumulation of data about the market and complicated calculations, which is too much effort for individual small investors. Therefore, portfolio selection with two significant financial ratios using the ELECTRE III method is proposed for these investors to make trading decisions. In order to demonstrate the effectiveness of this new method, it is compared to the situation where a fix percentage allocation existed and data was collected from the Stock Exchange of Thailand (SET).
\end{abstract}

\section{INTRODUCTION}

The Stock Exchange of Thailand (SET) is the national stock exchange of Thailand. Retail investors in Thailand have long been a majority of players. They account for approximately $41 \%$, whereas foreigner and institution flows are $36 \%$ and $21 \%$ of daily trading value respectively [13]. Since many factors (such as political and economic factors) are likely to influence the trend of the market [3], forecasting the trend requires various market analysis techniques [2, 5, $10,11,19,22]$. In addition, there are a number of machine learning techniques proposed as a solution to the problem such as reinforcement learning $[17,18,20]$, neural networks $[9,12]$, genetic algorithms $[1,15,16]$, decision trees [24], support vector machines [4, 14, 23], and boosting and expert weighting $[6,7,8]$. Arthur Samuel in 1959 defined machine learning as the "field of study that gives computers the ability to learn without being explicitly programmed". Such techniques build a model from an example training set of input observations in order to make data-driven predictions or decisions expressed as outputs. Although machine learning techniques are applied to interpret the status of the market and predict the market's future trend, but they are not beneficial to small investors because these techniques desire both accumulation of training data set about the market and complicated calculations to make data-driven predictions, which is too much effort for an individual small investor. Therefore, portfolio selection with only two significant financial ratios using the ELECTRE III method is proposed for those investors to make trading decisions. The two significant financial ratios are net profit margin and dividend yield. The Net profit margin is a ratio of profitability calculated as after-tax net income (net profits) divided by sales (revenue) and displayed as a percentage; whereby consideration focuses on stocks with high net profit margin. Dividend yield is the amount that a company pays to its shareholders annually for their investments; whereby consideration focuses on stocks with high dividend yield. It is expressed as a percentage and indicates attractiveness of investing in a company's stocks. The ELECTRE III method [21] is the most popular one of the outranking methods in Multi Criteria Decision Making (MCDM). Its performance of alternatives on each criterion in outranking is compared in pairs. An alternative a is said to outrank an alternative $b$ if it performs better on some criteria and at least as well as b on all others. The outranking relation in the ELECTRE III is a fuzzy binary relation. It uses three distinct thresholds (indifference, preference, and veto) to incorporate the uncertainties that are inherent in most influence valuations. In addition, the ELECTRE III method is less of a complex than the machine learning techniques because it follows strictly static program instructions.

This report proceeds as follow. In the next section, previous related literatures are reviewed. Then the research methodology and data used are discussed. Empirical results found in the study are then presented and analyzed. Lastly, conclusion, implications, and limitations together with suggestion for further study are presented.

\section{II.BACKGROUNDS}

An ELECTRE is a family of multi-criteria decision analysis methods (Roy, B. (1978)). The ELECTRE is working on the concrete, multiple criteria, and real-world problem of how firms can decide on new activities and had encountered problems using a weighted sum technique. It uses several mathematical functions to indicate the dominant degree of one alternative over the remaining ones. Additionally, it also facilitates comparisons between alternative schemes by using a weighted sum technique. The outranking relationships between alternatives are constructed and exploited eventually.

In order to be consistent with the basic concept of similarity in case based reasoning, different terminologies from the classical ELECTRE is used. 
Let the distance between case $a_{k}$ and case $a_{l}$ on the $j$ feature be denoted by $\left|a_{k j}-a_{l j}\right|$ or $d_{l k j}$. Let $w_{j}$ express the weight of the feature.

Definition 1: The indifferent threshold of criterion $j$ $q_{j}: a_{k}$ and $a_{l}$ are indifferent if $\left|a_{k j}-a_{l j}\right|<q_{j}$.

Definition 2: The strict preference threshold of criterion $\mathrm{j}$ $p_{j}: a_{k}$ is strictly preferred to $a_{l}$ if $\left|a_{k j}-a_{l j}\right|<q_{j}$.

Definition 3: The weak preference threshold of criterion $j$ $p_{j}: a_{k}$ is weakly preferred to $a_{l}$ if $\left|a_{k j}-a_{l j}\right| \leq p_{j}$.

Definition 4: The veto threshold of criterion $j v_{j}$ : reject the hypothesis of outranking of $a_{k}$ over $a_{l}$ if $\left|a_{k j}-a_{l j}\right|>v_{j}$.

\section{The Index of Concordance and Discordance}

Definition 5: The degree of concordance with the judgmental statement that $a_{k}$ outranks $a_{l}$ under the $j$ the criterion $c r_{j}(k, l)$ is defined as

$$
c r_{j}(k, l)=\left\{\begin{array}{l}
1 \quad \text { if } q_{j} \geq a_{l j}-a_{k j}, \\
0 \quad \text { if } p_{j} \leq a_{l j}-a_{k j}, \\
\frac{p_{j}-\left(a_{l j}-a_{k j}\right)}{p_{j}-q_{j}} \quad \text { otherwise }
\end{array}\right.
$$

Definition 6: A concordance index of each ordered pair $\left(a_{k}, a_{l}\right)$ of alternatives $\operatorname{cr}(k, l)$ is defined as

$$
\operatorname{cr}(k, l)=\frac{\sum_{j=1}^{r} w_{j} c r_{j}(k, l)}{\sum_{j=1}^{r} w_{j}}
$$

Where $w_{j}$ is the weight determining the relative importance of $j$ th criterion.

Definition 7: The degree of discordance with the judgmental statement that $a_{k}$ outranks $a_{l}$ under the $j$ the criterion $d_{j}(k, l)$ is defined as

$$
d_{j}(k, l)=\left\{\begin{array}{l}
0 \quad \text { if } a_{l j}-a_{k j} \leq p_{j}, \\
1 \quad \text { if } a_{l j}-a_{k j} \geq v_{j}, \\
\frac{\left(a_{l j}-a_{k j}\right)-p_{j}}{v_{j}-p_{j}} \quad \text { otherwise }
\end{array}\right.
$$

\section{The Degree of Outranking}

Definition 8: The degree of credibility of outranking with the judgmental statement that $a_{k}$ outranks $a_{l}$ is defined as

$$
s(k, l)=\left\{\begin{array}{l}
\operatorname{cr}(k, l) \quad \text { if } J(k, l)=\varnothing, \\
\operatorname{cr}(k, l) \prod_{j \in J(k, l)} \frac{1-d_{j}(k, l)}{1-c r(k, l)} \quad \text { otherwise }
\end{array}\right.
$$

where $J(k, l)$ is defined as the set of criterion for which $d_{j}(k, l)>c r(k, l)$. If $J(k, l)=\varnothing, \quad$ we have $d_{j}(k, l)>\operatorname{cr}(k, l)$ for any criterion, then $s(k, l)$ is the same as $\operatorname{cr}(k, l)$.

Definition 9: The ranking of the alternatives is defined as

$$
\delta_{k}=\sum_{l=1}^{n} s(k, l)-\sum_{l=1}^{n} s(l, k), k=1,2, \ldots, n
$$

\section{THE ELECTRE III MODEL FOR SELECTING STOCKS}

\section{A. The ELECTRE III Method}

Let $\mathrm{A}=\left\{\mathrm{a}_{1}, \mathrm{a}_{2}, \ldots \mathrm{a}_{\mathrm{n}}\right\}$ be a set of stock alternatives, $\mathrm{P}_{\text {purchase }}$ be prices of the purchased stocks in any year, $\mathrm{P}_{\text {sell }}$ be prices of the sold stocks in any year, and $\mathrm{C}=\left\{\mathrm{c}_{1}, \mathrm{c}_{2}\right\}$ be a set of criteria in this research which are net profit margin and dividend yield. $\mathrm{W}=\left\{\mathrm{w}_{1}, \mathrm{w}_{2}\right\}$ is a set of weights of influence on criteria net profit margin and dividend yield, $a_{k j}$ is the performance values of criterion $c_{j}$ of stock alternative $a_{k}$, and $\left(a_{k}, a_{j}\right)$ is any ordered pair of stock alternatives. Net Profits of any stocks are the difference between the price of the purchased stocks and their sold stocks. Total profit is summation of Net Profits and their Dividend yields.

In this section, Combinatorial Portfolio selection with the ELECTRE III method is described. There are three steps as follows:

Table 1: The ELECTRE III method for Selecting Stocks

Input: a list A of stock alternatives,

$\mathrm{P}_{\text {purchase }}$ is prices of the purchased stocks in any year,

$\mathrm{P}_{\text {sell }}$ is prices of the sold stocks in any year,

$\mathrm{C}$ is a set of criteria: net profit margin and dividend yield,

$\mathrm{W}$ is a set of weights of influence on criteria net profit margin and dividend yield,

Percent of ranking allocation

Output: Total profit of each allocation

1. Ranking the stocks. The results are ranking based on the ELECTRE III method.

2. Allocating percentage of top ranking stocks.

3. Calculating total profit from each allocation. 


\section{B. Description of the Scenario}

In this section, we present an application of the ELECTRE III method to select any stocks. Suppose that Somsri want to select stocks of any company. Table 2 shows all stocks that the she wants to purchase. Criteria that are considered in selecting each stock are their weights, their preference threshold, their indifference index, and their veto threshold are defined for this application, as in Table 3. The criteria net profit margin and dividend yield are to be maximized. The last price and dividend yield of stocks from 2011 to 2014 are shown in Table 4 and 5 respectively. Finally, the final ranking of the ELECTRE-III methods is shown in Table 6.
Table 2: Stock alternatives

\begin{tabular}{|c|c|}
\hline $\begin{array}{c}\text { Stock } \\
\text { alternatives }\end{array}$ & Description \\
\hline A1 & $\begin{array}{c}\text { BTS: BTS GROUP HOLDINGS } \\
\text { PUBLIC COMPANY LIMITED }\end{array}$ \\
\hline A2 & $\begin{array}{l}\text { PTT: PTT PUBLIC COMPANY } \\
\text { LIMITED }\end{array}$ \\
\hline A3 & $\begin{array}{ccc}\text { SPALI: } & \text { SUPALAI } & \text { PUBLIC } \\
\text { COMPANY LIMITED } & \end{array}$ \\
\hline A4 & $\begin{array}{l}\text { SCB: THE SIAM COMMERCIAL } \\
\text { BANK PUBLIC COMPANY LIMITED }\end{array}$ \\
\hline A5 & $\begin{array}{c}\text { AHC: } \text { AIKCHOL HOSPITAL } \\
\text { PUBLIC COMPANY LIMITED }\end{array}$ \\
\hline
\end{tabular}

Table 3: Indifference, preference, and veto thresholds values

\begin{tabular}{|l|c|c|c|c|c|c|}
\hline Criteria & Description & Units & $\begin{array}{c}\text { Indifference } \\
\text { Threshold (q) }\end{array}$ & $\begin{array}{c}\text { Preference } \\
\text { Threshold (p) }\end{array}$ & $\begin{array}{c}\text { Veto } \\
\text { Threshold (q) }\end{array}$ & Weight \\
\hline C1 & $\begin{array}{c}\text { Net Profit } \\
\text { Margin (\%) }\end{array}$ & $\%$ & 5 & 10 & 20 & 0.6 \\
\hline C2 & $\begin{array}{l}\text { Dividend Yield } \\
(\%)\end{array}$ & $\%$ & 0.5 & 3 & 5 & 0.3 \\
\hline
\end{tabular}

Table 4: Price of stocks of any company in any years

\begin{tabular}{|c|c|c|c|c|}
\hline \multirow[t]{2}{*}{ Alternatives } & \multicolumn{4}{|c|}{ Last Price(Baht) } \\
\hline & $30 / 12 / 2011$ & $28 / 12 / 2012$ & $27 / 12 / 2013$ & $30 / 12 / 2014$ \\
\hline A1: BTS & 0.7 & 7.15 & 8.70 & 9.65 \\
\hline A2: PTT & 318 & 332 & 286 & 324 \\
\hline A3: SPALI & 14.30 & 17.70 & 14.6 & 24.10 \\
\hline A4: SCB & 116.5 & 181.5 & 143.5 & 182.0 \\
\hline A5: AHC & 77.50 & 21.40 & 19.40 & 28.50 \\
\hline
\end{tabular}

Table 5: Dividend yields of stocks of the company in any years

\begin{tabular}{|l|l|l|l|l|}
\hline Alternatives & Dividend Yield (\%) & \multicolumn{2}{l|}{$30 / 12 / 2014$} \\
\hline & $30 / 12 / 2011$ & $28 / 12 / 2012$ & $27 / 12 / 2013$ & 6.2 \\
\hline A1: BTS & 5.03 & 3.55 & 4.21 & 4.01 \\
\hline A2: PTT & 3.21 & 3.91 & 4.55 & 2.9 \\
\hline A3: SPALI & 4.2 & 3.67 & 4.45 & 2.88 \\
\hline A4: SCB & 2.57 & 1.93 & 3.14 & 2.25 \\
\hline A5: AHC & 3.23 & 1.64 & 2.58 & \\
\hline
\end{tabular}


Table 6: Final rankings of the stock alternatives

\begin{tabular}{|l|l|}
\hline Stock Alternative & ELECTRE III \\
\hline A1: BTS & 3 \\
\hline A2: PTT & 5 \\
\hline A3: SPALI & 2 \\
\hline A4: SCB & 1 \\
\hline A5: AHC & 4 \\
\hline
\end{tabular}

Finally, we can rank stock alternatives. In ELECTRE III method, the best case is A4 and it is followed by A3, A1, A5, and $\mathrm{A} 2$ respectively.

\section{EMPIRICAL RESULTS AND ANALYSIS}

The empirical experiment to measure the total profit of ELECTRE III algorithm is conducted in this research. Several parameters are needed to be defined when applying the ELECTRE III algorithm:

\section{A. Experiment setting}

To demonstrate the effectiveness of the proposed schema the total profits under the two scenarios (that is, the ELECTRE-III method allocation and fixed-percentage allocation) are compared.

Then, assume that a budget is equal to 100,000 Thai Bahts. The number of years that the stock is hold is 4 years. The result of combination of two, three, four highest ranking stocks in the the ELECTRE-III method are shown in Tables 7, 8, and 9 below. Here, a fixed-percentage allocation of $20 \%$ has been assumed for all alternatives and are shown in Table 10.

Table 7: Results of the ELECTRE III method allocation with two highest ranking stocks (ELECTRE III (2))

\begin{tabular}{|c|c|l|l|l|l|l|l|l|}
\hline Stocks & Ranking & Percentage & Budgets & $P_{\text {purchased }}$ & Units & $P_{\text {sold }}$ & Profits & Total \\
\hline $\begin{array}{l}\text { A3: } \\
\text { SPALI }\end{array}$ & 2 & 50 & 50000 & 14.3 & 3496.50 & 24.1 & 9.88 & $87,762.24$ \\
\hline $\begin{array}{c}\text { A4: } \\
\text { SCB }\end{array}$ & 1 & 50 & 50000 & 116.5 & 429.18 & 182 & 65.5 & $32,626.61$ \\
\hline Total & & & & & & & & $120,388.8$ \\
\hline
\end{tabular}

Table 8: Results of the ELECTRE III method allocation with three highest ranking stocks (ELECTRE III (3))

\begin{tabular}{|c|c|c|c|c|c|c|c|c|}
\hline Stocks & Ranking & Percentage & Budgets & $\mathrm{P}_{\text {purchased }}$ & Units & $\mathrm{P}_{\text {sold }}$ & Profits & Total \\
\hline $\begin{array}{c}\text { A1: } \\
\text { BTS }\end{array}$ & 3 & 33.33 & 33333 & 0.7 & 47619.05 & 9.65 & 8.95 & $1,330,476$ \\
\hline A3: SPALI & 2 & 33.33 & 33333 & 14.3 & 2331 & 24.18 & 9.88 & $58,508.16$ \\
\hline $\begin{array}{c}\text { A4: } \\
\text { SCB }\end{array}$ & 1 & 33.33 & 333333 & 116.5 & 286.12 & 182 & 65.5 & $21,751.07$ \\
\hline Total & & & & & & & & $1,410,735$ \\
\hline
\end{tabular}

Table 9: Results of the ELECTRE III method allocation with four highest ranking stocks (ELECTRE III (4))

\begin{tabular}{|l|l|l|l|l|l|l|c|c|}
\hline Stocks & Ranking & Percentage & Budgets & $P_{\text {purchased }}$ & Units & P $_{\text {sold }}$ & Profits & Total \\
\hline A1: BTS & 3 & 25 & 25000 & 0.7 & $35,714.29$ & 9.65 & 8.95 & $997,857.1$ \\
\hline $\begin{array}{l}\text { A3: } \\
\text { SPALI }\end{array}$ & 2 & 25 & 25000 & 14.3 & $1,784.25$ & 24.18 & 9.88 & $43,881.12$ \\
\hline A4: SCB & 1 & 25 & 25000 & 116.5 & 214.59 & 182 & 65.5 & $16,313.3$ \\
\hline $\begin{array}{l}\text { A5: } \\
\text { AHC }\end{array}$ & 4 & 25 & 25000 & 77.5 & 322.58 & 28.5 & -4.9 & $-12,677.4$ \\
\hline \multicolumn{1}{c}{ Total } & & & & & & & & $1,045,374$ \\
\hline
\end{tabular}


Table 10: Results of the fixed-percentage allocation evaluation

\begin{tabular}{|c|c|l|l|l|l|l|l|l|}
\hline Stocks & Ranking & Percentage & Budgets & P $_{\text {purchased }}$ & Units & P $_{\text {sold }}$ & Profits & Total \\
\hline $\begin{array}{c}\text { A1: } \\
\text { BTS }\end{array}$ & 3 & 20 & 20000 & 0.7 & 28571 & 9.65 & 8.95 & 798285.7 \\
\hline $\begin{array}{c}\text { A2: } \\
\text { PTT }\end{array}$ & 5 & 20 & 20000 & 318 & 62.89 & 324 & 6 & 1363.52 \\
\hline $\begin{array}{l}\text { A3: } \\
\text { SPALI }\end{array}$ & 2 & 20 & 20000 & 14.3 & 1398.6 & 24.18 & 9.88 & $35,104.9$ \\
\hline $\begin{array}{c}\text { A4: } \\
\text { SCB }\end{array}$ & 1 & 20 & 20000 & 116.5 & 171.67 & 182 & 65.5 & $13,050.64$ \\
\hline $\begin{array}{c}\text { A5: } \\
\text { AHC }\end{array}$ & 4 & 20 & 20000 & 77.5 & 258.06 & 28.5 & -4.9 & $-10,141.9$ \\
\hline \begin{tabular}{c} 
Total \\
\hline
\end{tabular} & & & & & & & $837,662.86$ \\
\hline
\end{tabular}

To evaluate the performance of the ELECTRE-III method allocation the above algorithms were run 100 times for various simulation parameters and the average values of the profits were calculated. Table 11 shows various parameters used in the experiment.

Table 11: Simulation parameters used in both scenarios

\begin{tabular}{|l|l|}
\hline Parameters & $\begin{array}{c}\text { Range of values used for } \\
\text { simulation }\end{array}$ \\
\hline Fixed percentages & $20 \%$ \\
\hline Budgets & 100000 baths \\
\hline Years & $2-4$ years \\
\hline Alternatives & 5 \\
\hline
\end{tabular}

In Table 11, there are four parameters. Fixed percentage of a fixed-percentage allocation scheme is $20 \%$. Budget means the budget for all stocks or alternatives. Years mean the number of years that the stocks are hold from 2011 to 2014. Alternatives mean the number of stocks.

\section{B. Results}

The above results (Table 7, 8, and 9) show the total profits under the proposed scheme with different top-n choices. Figure 1 compares these results with a fixed-percentage allocation scheme (Table 10). In Figure 1, the vertical axis represents mean of total profit.

In these simulations, the total profits of the alternative ELECTRE-III (3) is higher than of the fixed-percentage allocation. To determine whether a significant difference exists between the total profits of the two groups, an independent t-test and a Wilcoxon signed rank statistic used with a significance level of $\alpha=0.05$ were applied to the results of these simulations. The test results reject the hypotheses: the total profit of the ELECTRE-III (3) is equal to of the fixed-percentage allocation. It implies that the total profit of the ELECTRE-III (3) is not equal to that of the fixed-percentage allocation comparisons. Additionally, the ELECTRE-III (4) method gives the same results as the ELECTRE-III (3) method. However, the ELECTRE-III (2) method gives the results opposite from the ELECTRE-III (3) because the number of stocks is not much to guarantee a risk from investment.

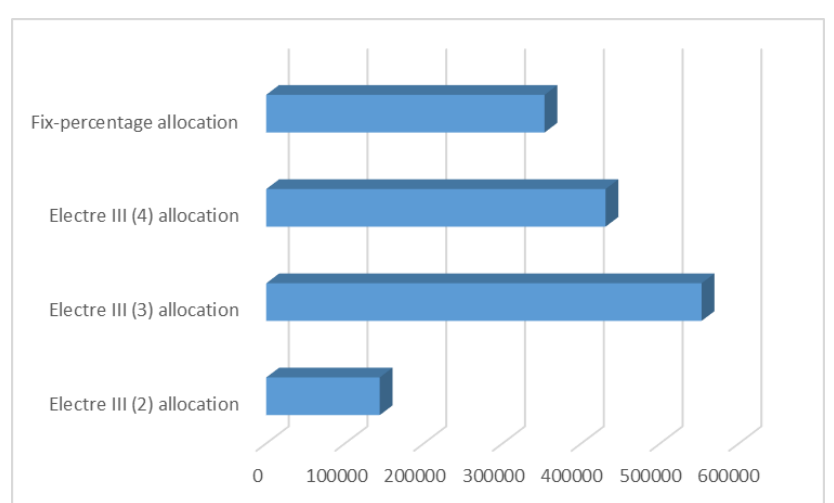

Figure 1: Results of satisfaction evaluation

\section{CONCLUSION, LIMITATIONS, AND FUTURE WORKS}

Portfolio selection with two significant financial ratios using the ELECTRE III method is proposed for small investors to make trading decisions. We have presented fundamental principles of the ELECTRE III method in detail. In this research, we use a veto indicator deriving from non-veto relations, weak veto relations, and strong veto relations to enhance the mechanism of similarity measure between two cases. 100 times is employed to assess ranking performance of various ELECTRE III methods. From the results of the experiment, we find that the new offer a viable approach for investment advisory ranking. Empirical results show that they offer significantly better ranking performance than the fix- 
percentage allocation method. Our proposed prototype using the ELECTRE III method has been successfully validated. This was demonstrated in Figure 1. Such results illustrate that user can get not vague information from application of the ELECTRE III method allocation to help he/she in investment planning and then it could lead to a growing total profits of retail investors in Thailand. Limitations of our study is that it doesn't considered situations with vary alternatives and percentages of ranking stocks.

\section{REFERENCES}

[1] Allen F, Karjalainen R. (1999). Using Genetic Algorithms to Find Technical Trading Rules. Journal of Financial Economics 51, 245-271.

[2] Basu S. (1977). Investment performance of common stocks in relation to their Price-Earnings ratios: a test of the efficient market hypothesis, Journal of Finance 32(3), 663-682.

[3] Boonyapatkul P (2011). Investor flows and stock return empirical evidence from stock exchange of Thailand, Master of Science Program in Finance (International Program), Faculty of Commerce and Accountancy Thammasat University, Bangkok, Thailand.

[4] Cao L J, Tay F E H. (2003). Support Vector Machine with Adaptive Parameters in Financial Time Series Forecasting. IEEE Transactions on Neural Networks 14(6), 1506-1518.

[5] Chan L K, Lakonishok J. (2004). Value and growth investing: review and update. Financial Analysts Journal 60(1), 71-86.

[6] Creamer G, Freund Y. (2007). A Boosting Approach for Automated Trading. Journal of Trading 2(3), 84-96.

[7] Creamer G. (2007). Using Boosting for Automated Planning And Trading Systems. Ph.D. Dissertation. Columbia University.

[8] Creamer G. (2012). Model Calibration and Automated Trading Agent for Euro Futures. Quantitative Finance 12(4), 531-545.

[9] Dempster M A H, Payne T W, Romahi Y, Thompson G W T. (2001). Computational Learning Techniques for Intraday FX Trading Using Popular Technical Indicators. IEEE Transactions on Neural Networks 12(4), 744-754.

[10] Fafuła A., Drelczuk K. (2015). Buying stock market winners on Warsaw Stock Exchange - quantitative backtests of a short term trend following strategy. In: Proceedings of Federated Conference Computer Science and Information Systems (FedCSIS), Wrocław, 1361-1366.

[11] Greenblatt J. (2006). The little book that beats the market, John Wiley \& Sons, Hoboken.

[12] Kimoto T, Asakawa K, Yoda M, Takeoka M. (2000). Stock Market Prediction System with Modular Neural Networks. Neural Networks in Finance and Investing, 343-357.

[13] Liu J N K, Leung T T S (2001). A Web-based CBR Agent for Financial Forecasting. In: Proceeding of the 4th International Conference on Case-Based Reasoning, 243-253.

[14] Lu C J, Lee T S, Chiu C C. (2009). Financial Time Series Forecasting Using Independent Component Analysis and Support Vector Regression. Decision Support Systems 47(2), 115-125.

[15] Mahfoud S, Mani G. (1996). Financial Forecasting Using Genetic Algorithms. Applied Artificial Intelligence 10, 543-565.

[16] Mandziuk J, Jaruszewicz M. (2011). Neuro-genetic System for Stock Index Prediction. Journal of Intelligent \& Fuzzy Systems 22, 93-123.

[17] Moody J, Saffell M. (2001). Learning to Trade via Direct Reinforcement. IEEE Transactions on Neural Networks 12 (4), 875889

[18] Moody J, Wu L, Liao Y, Saffell M. (1998). Performance Functions and Reinforcement Learning For Trading Systems and Portfolios. Journal of Forecasting 17, 441-471.

[19] Maneesilasan N. (2011). GARP Investing in Thailand., Working Paper, National Institute of Development Administra-tion, Bangkok.

[20] O J, Lee J W, Zhang B T. (2002). Stock Trading System Using Reinforcement Learning with Cooperative Agents. In Proceedings of the 19th International Conference on Machine Learning, 451-458.

[21] Roy B.: Electre III (1978). Algorithme de classement base sur une representation floue des preferences en presence de criteres multiples, Cahiers du CERO 20(1), 3-24

[22] Sareewiwatthana P. (2011). Value Investing in Thailand: The Test of Basic Screening Rules, International Review of Business Research Papers 7(4), 1-13.

[23] Tay F E H, Cao L J. (2002). Modified Support Vector Machines in Financial Time Series Forecasting. Neurocomputing 48, 847-861.

[24] Tsang E, Yung P, Li J. (2004). EDDIE-Automation, A Decision Support Tool for Financial Forecasting. Decision Support Systems 37, 559565. (Periodical style) 